\title{
Tipologia municipal de classes sociocupacionais: uma nova dimensão para análise das desigualdades territoriais no Brasil
}

\author{
Alexandre Gori Maia ${ }^{1}$ \\ Waldir José de Quadros²
}

\begin{abstract}
Resumo: O objetivo principal deste trabalho é propor uma nova configuração para o território brasileiro, fornecendo uma relevante dimensão para análise das desigualdades sociais no Brasil. A hipótese central é que a estrutura social, uma conjugação entre inserção no mercado de trabalho (classe ocupacional) e faixa de renda per capita (estrato social) das famílias brasileiras, é capaz de identificar padrões sociais que cumprem papéis essenciais nas análises sobre as extremas diferenças das condições de vida da população brasileira.
\end{abstract}

Palavras-chaves: estratificação social; renda-distribuição; disparidades regionais.

Abstract: The main purpose of this work is to propose a new configuration for the Brazilian territory, providing a relevant dimension to analyze Brazilian social inequalities. The central hypothesis is that the social structure, which consists of a combination between labor market position (occupational class) and per capita income level (social stratum) of Brazilian families, is able to identify social patterns which play an import role in analyzing the huge inequalities of living condition in Brazil.

Key-words: social stratification; income distribution; regional disparities;

Classificação JEL: J82; R12; R23.

\footnotetext{
$\overline{1}$ Pesquisador do Instituto de Economia da Universidade Estadual de Campinas (Unicamp). Email: gori@eco.unicamp.br

2 Professor do Instituto de Economia da Universidade Estadual de Campinas (Unicamp). Email: waldir.quadros@gmail.com
} 
Tipologia municipal de classes sociocupacionais:

uma nova dimensão para análise das desigualdades territoriais no Brasil

\section{Introdução}

A divisão do território em áreas urbanas e rurais tem se constituído como a mais tradicional e amplamente utilizada tipologia espacial para estudos socioeconômicos. O problema é que o Brasil não possui normas condizentes com sua complexa distribuição espacial e ainda vigoram no País regras para divisão territorial dos municípios herdadas do Estado Novo, de 1938. Tentando contornar essa situação, o IBGE (Instituto Brasileiro de Geografia e Estatística) ampliou, em 1991, a classificação espacial e, atualmente, trabalha com três categorias urbanas (urbanizadas, não-urbanizadas e urbano-isoladas) e quatro rurais (extensão urbana, povoado, núcleo e outros). Ainda prevalece, contudo, a obsoleta convenção de que toda sede de município é necessariamente espaço urbano, seja qual for sua função, dimensão ou situação (VEIGA et al., 2001).

$\mathrm{O}$ uso de metodologias alternativas de estratificação municipal, que captem com mais eficiência a imensa diversidade dos municípios brasileiros, torna-se, portanto, essencial para que a configuração territorial brasileira não permaneça na obscuridade. Nesse contexto, diversas tipologias podem ser obtidas empregando diferentes dimensões de análise (KAGEYAMA; LEONE; 1999; SEADE, 2003; VEIGA et al., 2001; IBGE, 2008), sendo que a eficiência de cada uma dependerá, sobretudo, dos propósitos da pesquisa.

Com o objetivo principal de fornecer uma nova e relevante dimensão para análise das desigualdades sociais, este trabalho propõe-se a elaborar uma nova configuração para o território brasileiro. Essa configuração será obtida a partir das estruturas sociais municipais, uma proposta de representação de grupos sociais relativamente homogêneos, considerando a inserção dos integrantes familiares no mercado de trabalho, bens e produtos, uma proxy para o comportamento de classes da sociedade brasileira.

A hipótese central desta análise é que, assim como os condicionantes históricos, culturais e ambientais influenciam o grau de desenvolvimento socioeconômico de uma região, os diferentes estágios de desenvolvimento regional determinam distintas estruturas sociais, exercendo papel fundamental na distribuição geográfica da população e, portanto, na configuração espacial da sociedade.

Compreender a distribuição espacial de dados oriundos de fenômenos ocorridos na população constitui hoje um grande desafio para a elucidação de questões centrais em diversas áreas de conhecimento (CAMARA et al., 2004). Da mesma forma que a configuração proposta colaborará, em certa medida, para identificar os diferentes graus de desenvolvimento socioeconômico que surgem da simples caracterização do espaço em áreas urbanas e rurais, permitirá ainda analisar o quadro de extremas desigualdades regionais brasileiras.

Embora as transformações socioeconômicas em curso nos municípios sejam importantes dinamizadores das mudanças na estrutura socioespaciais, devem-se 
também considerar as extremas desigualdades existentes no território brasileiro. Relacionando a tipologia municipal às características sociodemográficas, distribuição dos rendimentos e acesso à infra-estrutura domiciliar será ainda possível analisar a desigualdade dentro e entre grupos de municípios relativamente homogêneos, enriquecendo a análise dos conglomerados municipais.

Para cumprir com os objetivos propostos, os resultados deste trabalho serão apresentados em três blocos principais, além desta parte introdutória e das considerações finais: i) descrição da metodologia de estratificação social; ii) identificação dos grupos de municípios relativamente homogêneos de desenvolvimento da estrutura social (perfis sociais) e análise espacial desta configuração; iii) análise das desigualdades territoriais brasileiras, utilizando o perfil social como variável de controle.

\section{Estrutura social brasileira}

Estudos focalizados de identificação da pobreza e classificação da população segundo faixas de rendimentos dominam grande parte das discussões sobre políticas sociais no Brasil (NERI \& CARVALHAES, 2008; IPEA, 2008). Embora a renda possa definir a inserção dos indivíduos no mercado de bens e produtos, não pode ser vista como único fator delimitador da posição dos indivíduos na hierarquia de uma sociedade. Como alternativa à estratificação da população segundo faixas de rendimentos, a literatura social propõe tipologias baseadas em conceitos mais abrangentes, os quais seriam aproximações mais condizentes ao comportamento de classes de uma sociedade (ROSE \& PEVALIN, 2001; WRIGHT, 1985; VALLE SILVA, 1985).

Segundo MILLS (1979), a divisão social do trabalho passou a cumprir papel essencial na formação da estrutura das sociedades capitalistas modernas e o elemento marcante desse processo foi o surgimento de uma importante massa de trabalhadores assalariados de classe média. A idéia central é que a inserção ocupacional, além de definir em grande medida a probabilidade de geração presente e futura de renda dos indivíduos, passou também a associar-se com o prestígio social e à influência política proporcionada pela posição: o prestígio das relações sociais, seja pela simples maneira de se vestir aos relacionamentos com as autoridades; e o poder de exercer sua vontade e autoridade, seja diretamente sobre os subordinados de uma empresa, ou indiretamente sobre seu círculo social.

Inspirado na análise de MILLS (1979) sobre a sociedade norte-americana, QUADROS (2008) propõe uma estrutura para a sociedade brasileira baseada na divisão social do trabalho e elaborada a partir de informações das pesquisas domiciliares do IBGE. Tal metodologia parte do pressuposto que grupos sociais 
com estilos de vida relativamente homogêneos podem ser obtidos a partir da combinação entre a inserção dos integrantes familiares no mercado de trabalho (classes ocupacionais) e os rendimentos familiares per capita (estratos sociais).

A posição ocupacional do integrante familiar com o maior rendimento individual define a classe ocupacional da família, cuja identificação é dada em termos de poder político, prestígio social e possibilidade de geração de renda da posição. Esta estrutura pode ser representada por 14 classes ocupacionais:

Quadro 1. Descrição das classes ocupacionais familiares

\begin{tabular}{|c|c|c|}
\hline Sigla & Classe Ocupacional & Descrição \\
\hline A-1 & $\begin{array}{l}\text { Empregadores } \\
(>10)\end{array}$ & $\begin{array}{l}\text { Integrantes de famílias de empreendedores, dos mais } \\
\text { variados setores agrícolas e não-agrícolas, que empregam } \\
\text { mais de } 10 \text { trabalhadores. A PNAD não permite a } \\
\text { categorização de empregadores com mais de } 10 \\
\text { empregados, impedindo uma classificação mais apurada } \\
\text { dos grandes empregadores }\end{array}$ \\
\hline A-2 & $\begin{array}{l}\text { Empregadores } \\
(\leq 10)\end{array}$ & $\begin{array}{l}\text { Integrantes de famílias de pequenos empreendedores, } \\
\text { dos setores agrícolas e não-agrícolas, que empregam até } \\
10 \text { trabalhadores }\end{array}$ \\
\hline $\mathrm{C}$ & $\begin{array}{l}\text { Profissionais } \\
\text { autônomos }\end{array}$ & $\begin{array}{l}\text { Integrantes de famílias associadas a ocupações típicas de } \\
\text { classe média, onde predominam atividades relacionadas } \\
\text { ao comércio, escritório e prestação de serviços, exercidas } \\
\text { de forma independente pelo ocupado (vendedores e } \\
\text { demonstradores, supervisores, representantes } \\
\text { comerciais, entre outros) }\end{array}$ \\
\hline $\mathrm{D}$ & $\begin{array}{l}\text { Profissionais } \\
\text { assalariados }\end{array}$ & $\begin{array}{l}\text { Integrantes de famílias associadas a ocupações típicas de } \\
\text { classe média, em que predominam atividades relacionadas } \\
\text { ao comércio, escritório e prestação de serviços, exercidas } \\
\text { de forma assalariada pelo ocupado (auxiliares } \\
\text { administrativos, recepcionistas, professores, entre outros) }\end{array}$ \\
\hline $\mathrm{F}$ & $\begin{array}{l}\text { Trabalhadores } \\
\text { autônomos }\end{array}$ & $\begin{array}{l}\text { Integrantes de famílias associadas a ocupações } \\
\text { não-agrícolas de perfil operário ou assemelhado popular, } \\
\text { que são exercidas de forma independente pelo ocupado } \\
\text { (vendedores ambulantes, trabalhadores da construção } \\
\text { civil, prestadores de serviços na área de higiene e estética } \\
\text { corporal, entre outros) }\end{array}$ \\
\hline G & $\begin{array}{l}\text { Trabalhadores } \\
\text { assalariados }\end{array}$ & $\begin{array}{l}\text { Integrantes de famílias associadas a ocupações } \\
\text { não-agrícolas de perfil operário ou assemelhado popular, } \\
\text { que são exercidas de forma assalariada pelo ocupado } \\
\text { (zeladores e ascensoristas, ajudantes de obras, guardas e } \\
\text { vigias, entre outros) }\end{array}$ \\
\hline I & $\begin{array}{l}\text { Trabalhadores } \\
\text { domésticos }\end{array}$ & $\begin{array}{l}\text { Integrantes de famílias associadas ao trabalho no serviço } \\
\text { doméstico remunerado }\end{array}$ \\
\hline
\end{tabular}


Quadro 1. Continuação.

\begin{tabular}{|c|c|c|}
\hline Sigla & Classe Ocupacional & Descrição \\
\hline $\mathrm{H}-1$ & $\begin{array}{l}\text { Proprietários } \\
\text { agrícolas } \\
\text { conta-própria }\end{array}$ & $\begin{array}{l}\text { Integrantes de famílias associadas à pequena produção } \\
\text { no ramo da agricultura ou pecuária familiar realizada } \\
\text { sem o emprego de mão-de-obra assalariada }\end{array}$ \\
\hline $\mathrm{H}-2$ & $\begin{array}{l}\text { Trabalhadores } \\
\text { agrícolas } \\
\text { autônomos }\end{array}$ & $\begin{array}{l}\text { Integrantes de famílias associadas a profissões agrícolas } \\
\text { exercidas de forma autônoma (pescadores, caçadores, } \\
\text { extrativistas, entre outros) }\end{array}$ \\
\hline $\mathrm{H}-3$ & $\begin{array}{l}\text { Trabalhadores } \\
\text { agrícolas } \\
\text { assalariados }\end{array}$ & $\begin{array}{l}\text { Integrantes de famílias associadas a profissões agrícolas } \\
\text { exercidas de forma assalariada permanente ou } \\
\text { temporária (bóia-fria) }\end{array}$ \\
\hline $\mathrm{J}-1$ & $\begin{array}{l}\text { Trabalhadores } \\
\text { não-agrícolas } \\
\text { não-remunerados }\end{array}$ & $\begin{array}{l}\text { Integrantes de famílias associadas ao trabalho } \\
\text { não-remunerado em atividades não-agrícolas exercidas } \\
\text { durante pelo menos uma hora por semana em ajuda a } \\
\text { membro do domicílio, aprendiz, estagiário ou na } \\
\text { construção para o próprio. }\end{array}$ \\
\hline $\mathrm{J}-2$ & $\begin{array}{l}\text { Trabalhadores } \\
\text { agrícolas } \\
\text { não-remunerados }\end{array}$ & $\begin{array}{l}\text { Integrantes de famílias associadas ao trabalho em } \\
\text { atividades agrícolas exercidas durante pelo menos uma } \\
\text { hora por semana em auxílio à produção familiar ou na } \\
\text { produção de bens para o próprio consumo. }\end{array}$ \\
\hline SO & $\begin{array}{l}\text { Sem ocupação } \\
\text { com renda }\end{array}$ & $\begin{array}{l}\text { Integrantes de famílias dependentes de um membro sem } \\
\text { ocupação na semana, mas com rendimento proveniente } \\
\text { de fonte não relacionada ao trabalho (aposentados, em } \\
\text { sua maioria) }\end{array}$ \\
\hline $\mathrm{SOF}$ & $\begin{array}{l}\text { Sem ocupação } \\
\text { sem renda }\end{array}$ & $\begin{array}{l}\text { Integrantes de famílias sem membros ocupados e sem } \\
\text { qualquer fonte regular de rendimento }\end{array}$ \\
\hline
\end{tabular}

A declaração de conta própria ou empregado para a posição na ocupação do integrante melhor remunerado define a classificação ocupacional de autônomo (C, F, H-1 e H-2) ou assalariado (D, G e H-3). Por sua vez, a distinção entre as classes dos profissionais ( $\mathrm{C} \mathrm{e} \mathrm{D)} \mathrm{e} \mathrm{trabalhadores} \mathrm{não-agrícolas} \mathrm{(F} \mathrm{e} \mathrm{G),} \mathrm{assim} \mathrm{como}$ entre proprietários agrícolas conta própria $(\mathrm{H}-1)$ e trabalhadores autônomos agrícolas (H-2), considera, essencialmente, o status das ocupações. Algumas distinções são claras, como o advogado que é um profissional e o garçom que é um trabalhador. Outras ocupações com prestígio social não tão evidente, como vendedores ( $C$ e $D)$ e repositores no comércio ( $F$ e $G$ ), são classificadas considerando o comportamento dos rendimentos médios individuais em vários períodos de análise.

Já a classe formada pelas pessoas de famílias sem ocupação com renda representa mais um conjunto disperso de pequenos grupos que uma categoria social única, podendo ser melhor compreendida se analisada paralelamente. Não são como os profissionais autônomos, ou trabalhadores assalariados, que 
394 - Tipologia municipal de classes sociocupacionais:

uma nova dimensão para análise das desigualdades territoriais no Brasil

podem ser considerados agrupamentos sociais, cada um com oportunidades relativamente semelhantes de geração de renda, prestígio e poder político. Os aposentados, responsáveis por parcela majoritária das famílias desta classe, não possuem uma origem comum, tampouco o mesmo destino social. Como as chances de vida de um aposentado e sua família dependem, além da posse ou não de propriedade e ao acesso a uma série de direitos sociais, da ocupação em que se aposentou, o ideal seria sua classificação segundo sua antiga posição ocupacional. Entretanto, como a base de dados utilizada na pesquisa não permitia identificar a posição ocupacional da maior parte daqueles com renda que pararam de trabalhar, restringiu-se sua classificação a um grupo genérico aqui denominado sem ocupação com renda.

Classificando as famílias, não os indivíduos, pressupõe-se que o estilo de vida e as características sociais dos indivíduos são, em grande medida, definidas no âmbito das relações familiares, não das posições individuais. Considera-se, desta maneira, a interação social entre indivíduos de uma mesma família mais importante que a interação entre indivíduos de uma mesma classe ocupacional individual. Outro importante resultado desta classificação familiar é a incorporação dos inativos na estrutura social. Sem a classificação familiar não seria possível, por exemplo, considerar o número de dependentes de cada classe ocupacional, tampouco aquelas famílias associadas a rendimentos não provenientes do trabalho ou sem qualquer fonte de remuneração.

Embora a distribuição das classes ocupacionais seja um importante indicador do estilo de vida das pessoas, não podem ser desconsideradas significativas distinções no nível de bem-estar das famílias que podem surgir dentro de cada um destes agrupamentos sociais. Esta desigualdade é ainda mais acentuada pelo fato de se tratar de uma sociedade notadamente heterogênea como a brasileira, na qual, mesmo em grupos sociais com oportunidades relativamente homogêneas, é comum encontrar significativas distorções distributivas. E, como afirma ROCHA (2002:1)

"[...] apesar dos conhecidos problemas conceituais e metodológicos a serem necessariamente enfrentados quando se trata de mensurar a renda, ela é reconhecidamente a melhor proxy de bem-estar, pelo menos no que diz respeito àquele que deriva do consumo no âmbito privado". (ROCHA, 2002, p.1).

A classificação interna das classes ocupacionais segundo faixas de renda cumpriria, desta forma, um importante papel de distinção do nível de bem-estar de um mesmo grupo social. Tendo como referência um valor próximo ao salário mínimo de janeiro de $2005^{3}$, período de referência das análises, definiram-se faixas normativas de renda familiar per capita declarada mais ou menos

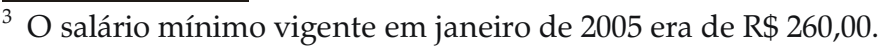


condizentes com distintos padrões de vida de uma família brasileira e que, ao mesmo tempo, discriminassem parcelas diferenciadas da população, próximas aos $40 \%$ relativamente mais pobres, próximos $25 \%$ mais pobres, $20 \%, 10 \%$ e, finalmente, os $5 \%$ relativamente mais ricos. Assim, a partir de múltiplos de 265 reais, a população foi ainda desagregada em 5 estratos sociais definidos pelos rendimentos familiares per capita:

Quadro 2. Estratos sociais

\begin{tabular}{|c|c|}
\hline Estrato Social & Renda familiar per capita \\
\hline Superior & Acima de $\mathrm{R} \$ 1.325,00$ \\
Médio & Entre $\mathrm{R} \$ 662,50$ e $\mathrm{R} \$ 1.325,00$ \\
Baixo & Entre $\mathrm{R} \$ 265,00$ e $\mathrm{R} \$ 662,50$ \\
Inferior & Entre $\mathrm{R} \$ 132,50$ e $\mathrm{R} \$ 265,00$ \\
Ínfimo & Abaixo de $\mathrm{R} \$ 132,50$ \\
\hline
\end{tabular}

Valores de janeiro de 2005

Fonte: Elaboração própria

Deve-se destacar que a hierarquização das classes sociocupacionais (a combinação das classes ocupacionais aos estratos sociais) não representa uma escala medindo a capacidade de mercado de diferentes setores da sociedade, mas, sim, uma aproximação dos padrões sociais determinado pela inserção dos integrantes familiares no mercado de trabalho. Por se tratar de uma representação das relações sociais, não há entre as classes ocupacionais e estratos sociais uma hierarquização linear, ou seja, embora alguns grupos estejam subordinados a outros, não é possível quantificar esta relação. A estrutura social permite, entretanto, identificar diferentes relações da sociedade e do mercado de trabalho latentes aos grupos identificados. Sua distribuição para a população brasileira em 2000 pode ser observada no Apêndice A, sendo referência para a elaboração da tipologia municipal a ser apresentada no próximo tópico.

\section{Grupos municipais de desenvolvimento da estrutura social}

\subsection{Perfis sociais}

Os 5.507 municípios presentes na base de microdados do Censo Demográfico 2000 foram cruzados às 14 classes ocupacionais (A-1, A-2, C, D, F, G, I, H-1, H-2, H-3, J-1, J-2, SO, SOF) e aos 5 estratos sociais (Superior, Médio, Baixo, Inferior e Ínfimo) para formar as estruturas sociais municipais. A partir destas estruturas, os grupos municipais de desenvolvimento da estrutura social, ou simplesmente perfis sociais, foram elaborados com o emprego conjunto das técnicas estatísticas 
396 - Tipologia municipal de classes sociocupacionais:

uma nova dimensão para análise das desigualdades territoriais no Brasil

multivariadas de análise de correspondência múltipla (ACM) e análise de cluster (AC). Enquanto a ACM possibilitou a redução da estrutura de relacionamentos entre os atributos qualitativos de interesse, a AC permitiu a agregação de características relativamente homogêneas para constituição dos perfis sociais.

A partir de uma tabela de contingência com múltiplas combinações de categorias qualitativas (tabela de Burt), a ACM elimina o uso de informaçóes redundantes e determina o número de dimensões pertinentes a serem consideradas para se compreender a estrutura de associações entre as categorias de análise. A ACM se baseia na técnica de componentes principais para simplificar a estrutura dos dados, explicando em um número reduzido de dimensões a maior parcela de informação presente nos dados (CUADRAS, 1981). Após identificar as principais dimensões (componentes) representativas da variação dos dados, a $\mathrm{ACM}$ viabiliza a representação gráfica da estrutura de associações e o emprego de técnicas de agrupamento para definir a tipologia de associações existentes entre as categorias.

A AC, por sua vez, procura definir grupos hierárquicos de observações dentro de um conjunto de dados. Há uma série de métodos que podem ser empregados neste processo, mas todos se baseiam no mesmo princípio de agrupamentos hierárquicos. No início do processo, cada elemento da amostra representa um cluster. Os dois clusters mais próximos são unidos para formar um novo cluster que os substitui e assim sucessivamente, até que reste apenas um ou o número máximo preestabelecido pelo pesquisador. A diferença entre os métodos está basicamente na maneira como a distância (ou dissimilaridade) entre os clusters é calculada. O método de agrupamento adotado neste trabalho foi o de Ward, uma estratégia de agregação baseada na análise das variâncias dentro e entre os grupos formados. O objetivo deste método é criar grupos hierárquicos de tal forma que as variâncias dentro dos grupos sejam mínimas e as variâncias entre os grupos sejam máximas (CRIVISQUI, 1999). O critério de agregação consiste em encontrar o próximo agrupamento que minimize a variabilidade dentro do novo grupo. Para facilitar a compreensão da variabilidade dentro dos grupos, estas costumam ser dividas pela variabilidade total para representarem uma proporção da variabilidade máxima obtida $\left(R^{2}\right.$ semiparcial).

A tabela de Burt, contendo as freqüências observadas para os múltiplos relacionamentos entre municípios, classes ocupacionais e estratos sociais, foi utilizada pela ACM para reduzir a dimensionalidade dos dados e viabilizar a identificação de grupos de municípios relativamente homogêneos. As duas principais dimensões resultantes dessa técnica foram utilizadas pela AC para classificar as categorias de municípios, classes ocupacionais e estratos sociais segundo o princípio da mínima variabilidade dentro dos grupos formados. 
Os coeficientes de dissimilaridade ( $R^{2}$ semiparciais) associados aos últimos estágios de agrupamento da AC podem ser observados na Figura $1^{4}$. Baseado nos valores dos coeficientes e na eficiência analítica associada a cada número de grupos, optou-se pela adoção de seis grupos municipais. Como pode ser observada pela Figura 1, a redução no grau de dissimilaridade torna-se relativamente estável a partir do sexto cluster, além de ser esse o número mínimo necessário para distinguir eficientemente as principais classes ocupacionais: empregadores; profissionais; massa trabalhadora não-agrícola; e massa trabalhadora agrícola.

Figura 1. Coeficiente de dissimilaridade $\left(\mathrm{R}^{2}\right.$ semiparcial $)$ segundo número de clusters

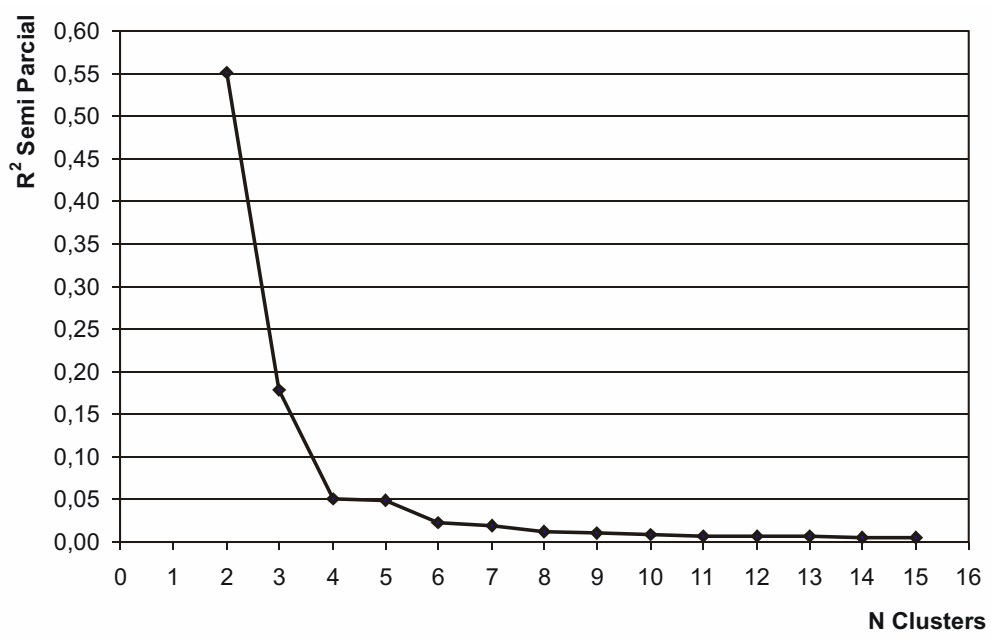

Fonte: Censo Demográfico 2000, microdados, IBGE. Elaboração dos autores.

A estrutura de associações com a distribuição das principais categorias de análise no espaço euclidiano formado pelas duas principais dimensões da ACM pode ser visualizada na Figura 2. Grupos de categorias próximas revelam similaridades nas associações, enquanto grupos distantes significam repulsão entre as categorias. Os 5.507 municípios foram representados por quatro pontos cardeais identificando a dispersão dentro de cada grupo. Assim, considerando as duas dimensões da ACM, $1^{\mathrm{a}}$ e $2^{\mathrm{a}}$, representadas no plano euclidiano pelos eixos das abscissas e ordenadas, respectivamente, cada grupo de municípios foi

${ }^{4}$ A dissimilaridade associada a apenas 1 grupo de análise, com $R^{2}$ semiparcial equivalente a $100 \%$ da variabiblidade total, foi desconsiderada para dar mais ênfase às variações dos coeficientes. 
representado pelos pontos: i) Norte, correspondente ao maior valor da $2^{\mathrm{a}}$ dimensão e ao valor central da $1^{\mathrm{a}}$ dimensão; ii) Sul, com o menor valor da $2^{\mathrm{a}}$ dimensão e o valor central da $1^{\underline{a}}$ dimensão; iii) Oeste, com o menor valor $1^{\underline{a}}$ dimensão e o valor central da $2^{a}$ dimensão; iv) Leste, com o maior valor da $1^{\underline{a}}$ dimensão e o valor central da $2^{a}$ dimensão. Dessa forma, os municípios do grupo 1 , por exemplo, foram representados pelos pontos N1 (Norte do grupo 1), S1 (Sul do grupo 1), L1 (Leste do grupo 1) e O1 (Oeste do grupo 1).

A análise da estrutura de associação da Figura 2 sugere a existência de seis grupos municipais que seguem uma clara hierarquia de associações em relação às classes ocupacionais e aos estratos sociais. Enquanto os municípios dos grupos $1 \mathrm{e}$ 2 apresentam uma estrutura associada às classes não-agrícolas e aos quatro primeiros estratos sociais (superior, médio, baixo e inferior), os grupos 3, 4, 5 e 6 estão mais associados às classes agrícolas e ao estrato ínfimo.

Figura 2. Dimensões de correspondências entre municípios, classes ocupacionais e estratos sociais

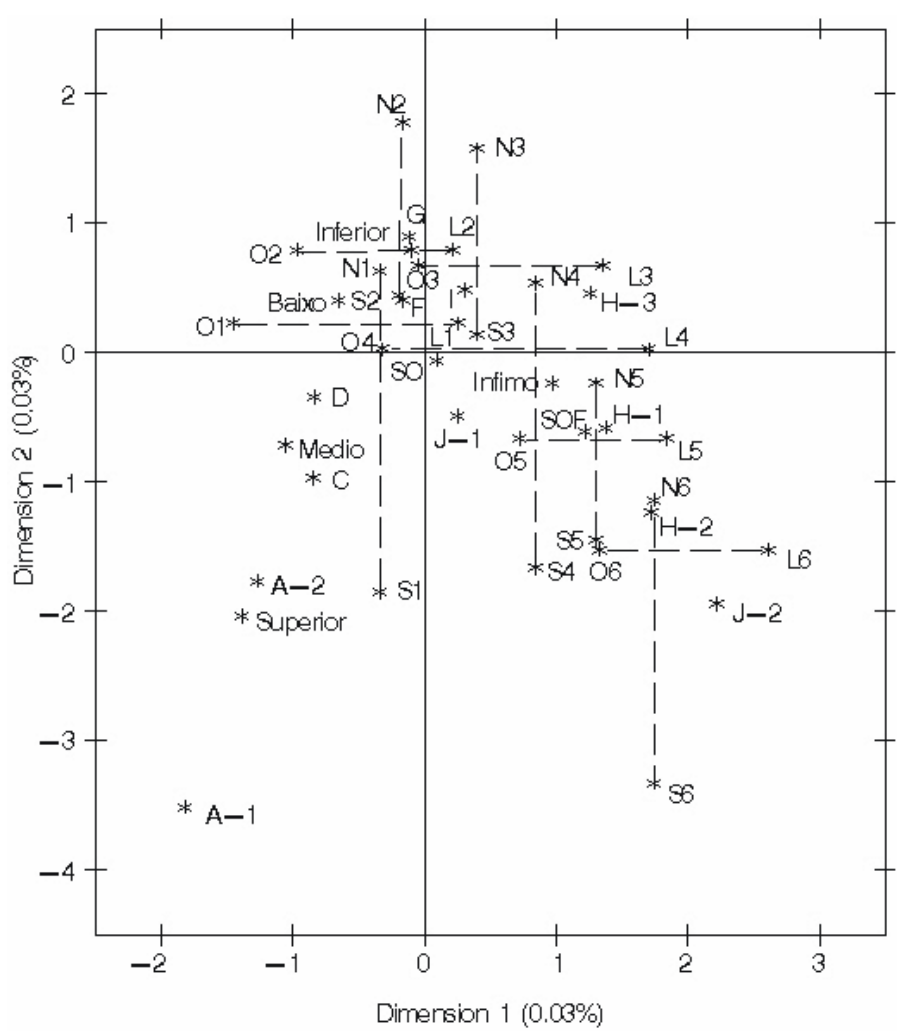

Fonte: Censo Demográfico 2000, microdados, IBGE. Elaboração dos autores. 
Embora a classificação obtida não permita quantificar as relações entre os municípios brasileiros, permite identificar uma clara hierarquia de desenvolvimento socioeconômico entre os perfis sociais. Da primeira à última categoria municipal, a tendência é a redução do desenvolvimento socioeconômico, com uma progressiva participação das classes ocupacionais relacionadas às atividades agrícolas, dos pobres e miseráveis pertencentes aos estratos inferior e ínfimo. Enquanto os municípios do grupo 1 estariam inseridos na terceira onda de desenvolvimento econômico, com predomínio das atividades relacionadas à prestação de serviços e de maior prestígio social, os municípios do grupo 2 estariam na fase de industrialização, com predomínio de atividades de menor prestígio social, e os demais grupos $(3,4,5$ e 6$)$ estariam associados ao desenvolvimento do setor primário.

É importante destacar que essa tipologia municipal se refere a participações relativas na estrutura social, associadas, por sua vez, ao grau de desenvolvimento socioeconômico dos municípios, e não a concentrações absolutas da população. Não significa, por exemplo, que o maior contingente populacional de subclassificados esteja nos grupos 3,4,5e 6, mas, sim, que a estrutura social pouco diversificada desses municípios não possibilita muitas alternativas econômicas à parcela expressiva de suas populações ${ }^{5}$. Da mesma forma, é possível que municípios com predomínio de atividades tipicamente agrícolas apresentem alguns bons indicadores de qualidade de vida, embora não seja esse o padrão vigente na maioria dessas populações, nas quais prevalecem marginalizados do estrato ínfimo e baixos padrões sociais.

A Tabela 1 apresenta a estrutura social para o conjunto dos municípios de cada perfil social, a partir da qual será elaborada uma análise mais apurada dos grupos municipais. Para simplificar a visualização e análise dos resultados, as classes ocupacionais foram agrupadas em: i) empregadores (A-1 e A-2); ii) profissionais (C e D); iii) massa trabalhadora não-agrícola (F, G e I); iv) massa trabalhadora agrícola (H-1, H-2 e H-3); v) trabalhadores não-remunerados não-agrícolas (J-1); vi) trabalhadores não-remunerados agrícolas (J-2); vii) sem ocupação com renda (SO); e viii) sem ocupação sem renda (SOF). Da mesma forma, os estratos sociais internos às classes ocupacionais foram agrupados em: i) classificados (estratos superior, médio e baixo) e ii) subclassificados (estratos inferior e ínfimo). A participação de todas as classes ocupacionais em cada perfil municipal pode ainda ser observada no Apêndice B.

\footnotetext{
${ }^{5}$ Por exemplo, o contingente de subclassificados (estratos inferior e ínfimo) da tipologia mais desenvolvida (perfil social 1) é de 39 milhões de pessoas (38\% do total de subclassificados do País), que representa $46 \%$ da população deste grupo, enquanto que o contingente de subclassificados da tipologia menos desenvolvida é de apenas 4,2 milhões de pessoas ( $4 \%$ do total de suclassificados do País), mas que representa 95\% de sua população.
} 
Resumidamente, os perfis sociais podem ser assim definidos:

Grupo 1-Municípios de profissionais: pertencem a este grupo os municípios com o maior grau de desenvolvimento da estrutura social. Possuem mais de $3 / 4 \mathrm{da}$ população nas classes ocupacionais tipicamente urbanas, com destaque para a participação dos empregadores $(4 \%)$ e profissionais $(32 \%)$, além de uma significativa parcela na classe da massa trabalhadora não-agrícola $(41 \%)$. De maneira geral, apresenta um padrão de vida típico de classe média, com $54 \%$ da população nos estratos superior, médio e baixo.

Grupo 2 - Municípios de operários: também apresentam uma população majoritariamente não-agrícola, com quase $3 / 4$ da população nas classes tipicamente urbanas, e se destacam, sobretudo, pela expressiva participação de integrantes de famílias da massa trabalhadora não-agrícola (50\%). Distinguem-se ainda dos municípios de profissionais pela maior parcela de subclassificados nas principais classes ocupacionais. De maneira geral, apresentam $54 \%$ da população nos estratos inferior e ínfimo.

Grupo 3 - Municípios agrícolas urbanizados: municípios que, embora apresentem uma expressiva participação da população nas classes agrícolas (20\%), estão em processo relativamente avançado de urbanização, com $20 \%$ de integrantes de famílias de profissionais e $40 \%$ de trabalhadores não-agrícolas em sua estrutura social. Entre os grupos de municípios agrícolas (perfis sociais 3, 4, 5e 6), apresenta a menor parcela de pobres e miseráveis dos estratos inferior e ínfimo, mesmo estes representando praticamente $3 / 4$ da população. Distinguem-se, ainda, dos demais perfis agrícolas pela própria composição da massa trabalhadora agrícola, com maior percentagem de integrantes de famílias de assalariados (H-3 sendo 13,4\%) e as menores participações relativas de integrantes de famílias de conta própria (H-1 sendo 6\%) e não-remunerados (J-2 sendo $1 \%)$.

Grupo 4 - Municípios de trabalhadores agrícolas: municípios que possuem praticamente $30 \%$ da população nas classes agrícolas e menor participação das classes não-agrícolas em relação aos municípios do grupo 3. Distinguem-se ainda destes municípios pela própria composição interna da massa trabalhadora agrícola, sobretudo, pela maior participação de integrantes da classe de trabalhadores conta própria (12\%) e não-remunerados (3\%), assim como uma maior parcela de subclassificados (83\% contra $73 \%$ do grupo 3 ).

Grupo 5-Municípios agrícolas conta própria: possuem 73\% de miseráveis do estrato ínfimo e uma expressiva parcela da população nas classes agrícolas (30\% na massa trabalhadora e 10\% de não-remunerados). Entre os perfis agrícolas, destaca-se pela maior participação de pequenos proprietários agrícolas conta própria, que representam 19\% da população. 
Grupo 6-Municípios agrícolas autoconsumo: na base da pirâmide social estão esses municípios rurais autoconsumo, no qual as classes de trabalhadores agrícolas representam quase metade da população, com uma expressiva participação de integrantes de famílias de não-remunerados agrícolas (22\%). Apresentam ainda as maiores taxas de subclassificados e, de maneira geral, 83\% de miseráveis do estrato ínfimo na população.

O primeiro fato a destacar é a configuração principal entre os perfis tipicamente agrícolas e não-agrícolas, bem como a distinção interna que há entre esses. Enquanto os municípios não-agrícolas se distinguem entre si pelo predomínio das classes relacionadas à prestação de serviços ou a ocupações não-agrícolas de menor prestígio social, nos municípios tipicamente agrícolas a maior distinção está na participação de integrantes de famílias de proprietários conta própria, trabalhadores autônomos e assalariados da massa trabalhadora agrícola. Enquanto a massa de assalariados tende a reduzir a participação de subclassificados nos municípios tipicamente agrícolas, a recíproca ocorre em relação à classe dos proprietários conta própria, que está associada à maior participação de pobres e miseráveis na estrutura social.

Outra importante conclusão dessa estratificação é a complementaridade dos critérios de classificação ocupacional e econômica. Da mesma forma que a distribuição das classes ocupacionais de um município determina, em grande medida, a distribuição dos estratos sociais, ela está também associada à parcela de classificados e subclassificados dentro de uma mesma classe ocupacional. Tal fato sugere que o estágio de desenvolvimento socioeconômico de um município é responsável não só pela composição da estrutura ocupacional da sociedade, como também pelas diferentes oportunidades de geração de renda dentro de uma mesma classe. A maior participação de profissionais e empregadores nos municípios não-agrícolas, por exemplo, está associada ao maior estágio de desenvolvimento socioeconômico desses municípios, que também influencia a maior participação relativa de classificados em relação aos subclassificados em praticamente todas as classes ocupacionais. 
402 - Tipologia municipal de classes sociocupacionais:

uma nova dimensão para análise das desigualdades territoriais no Brasil

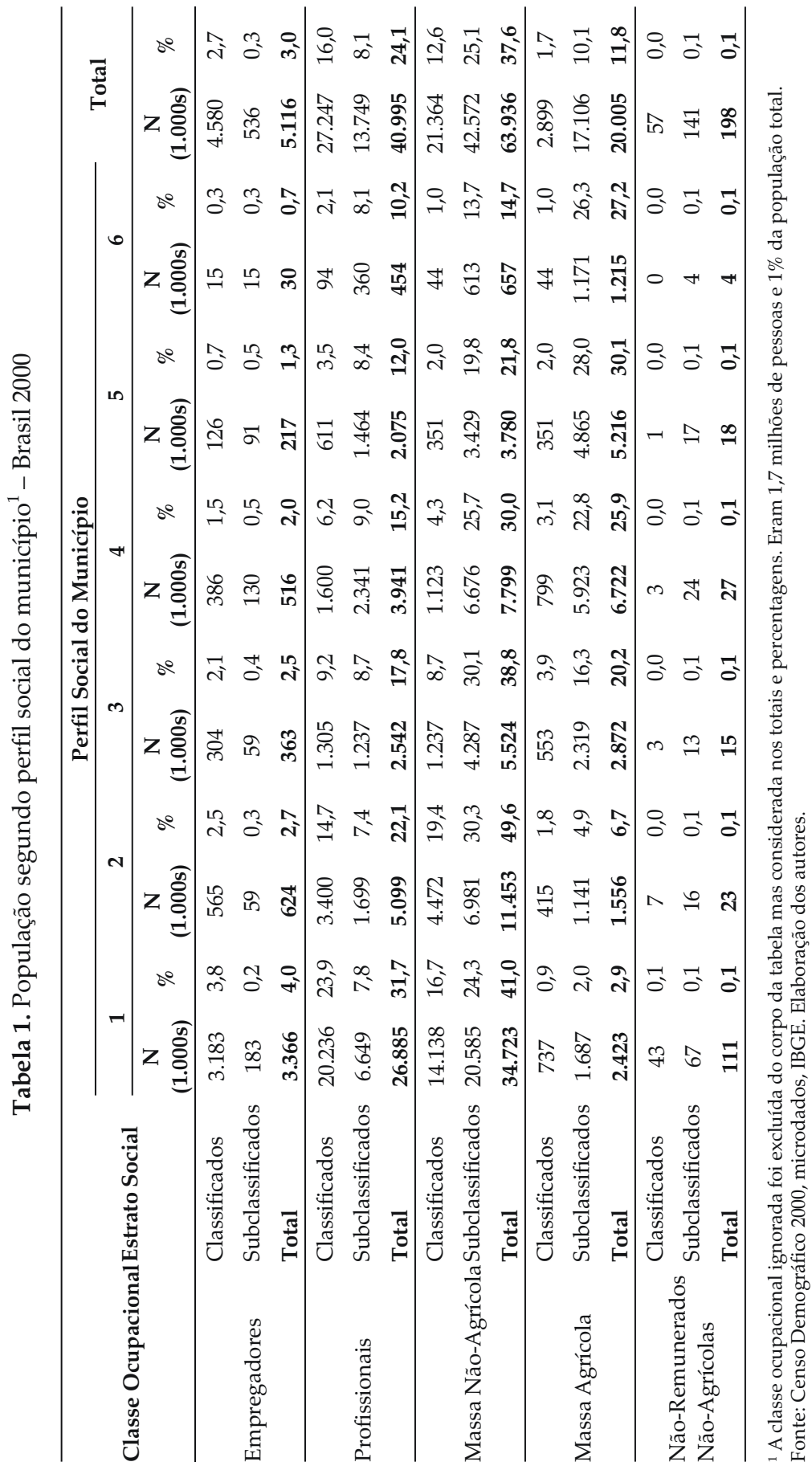

RESR, Piracicaba, SP, vol. 47, no 02, p. 389-418, abr/jun 2009 - Impressa em julho 2009 


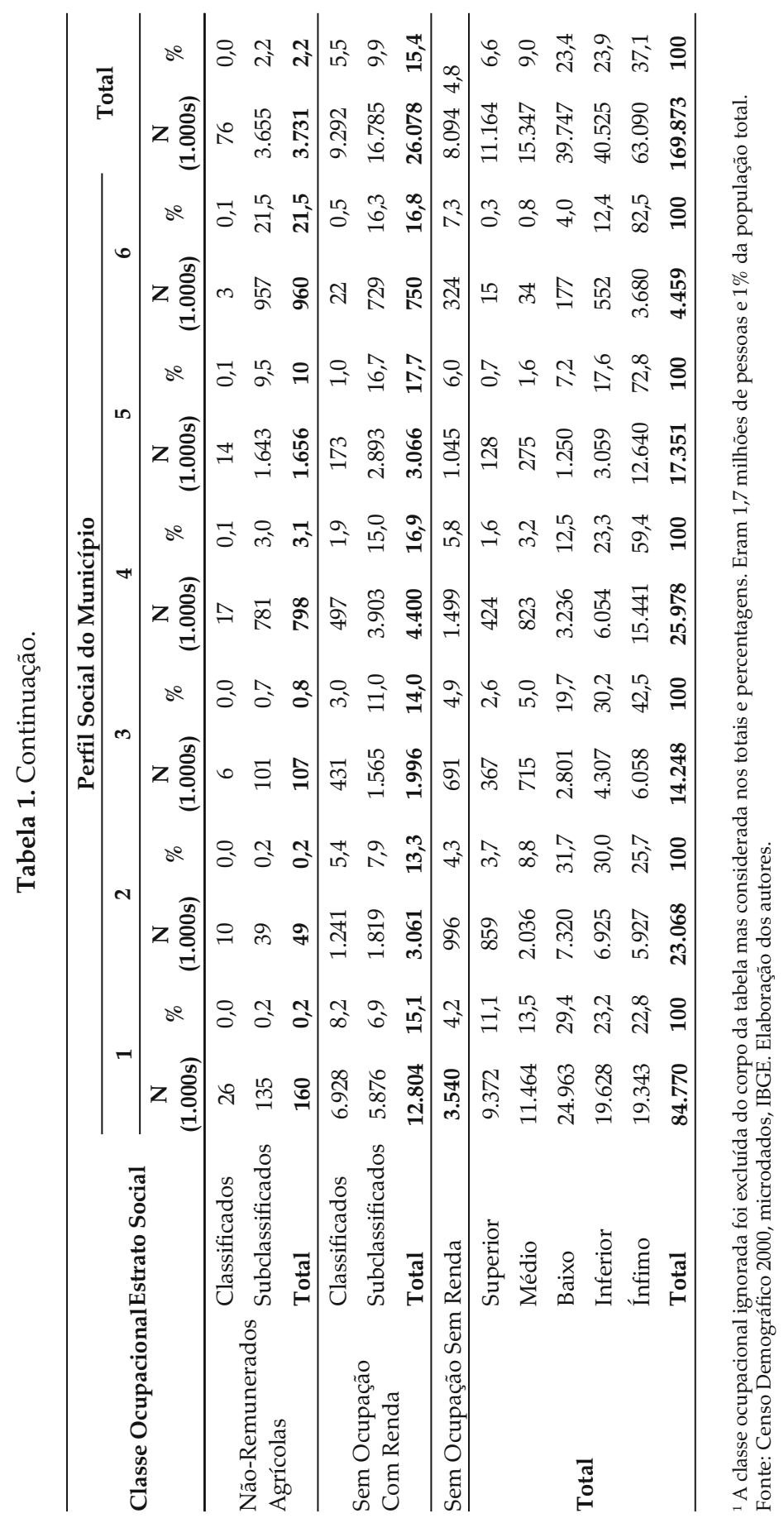

RESR, Piracicaba, SP, vol. 47, no 02, p. 389-418, abr/jun 2009 - Impressa em julho 2009 
404 - Tipologia municipal de classes sociocupacionais:

uma nova dimensão para análise das desigualdades territoriais no Brasil

\subsection{Distribuição espacial de classes}

Áreas territoriais de desenvolvimento e atraso relativo da estrutura social podem ser identificadas a partir do mapa coroplético exibido na Figura 3, que contém a distribuição espacial dos 5.507 municípios brasileiros segundo perfis sociais. De maneira geral, constata-se a concentração de municípios rurais dos dois últimos estágios de desenvolvimento (grupos 5 e 6) na fronteira ocidental da Amazônia brasileira, na região do Sertão nordestino e no estado do Maranhão. Já as áreas mais contíguas de municípios não-agrícolas aparecem, sobretudo, nos estados de São Paulo, Rio de Janeiro, no leste da região Sul e em uma faixa do sul de Goiás e sudoeste de Minas Gerais, seguindo um aparente prolongamento do processo de desenvolvimento observado no oeste paulista.

Figura 3. Distribuição espacial dos municípios segundo perfil social

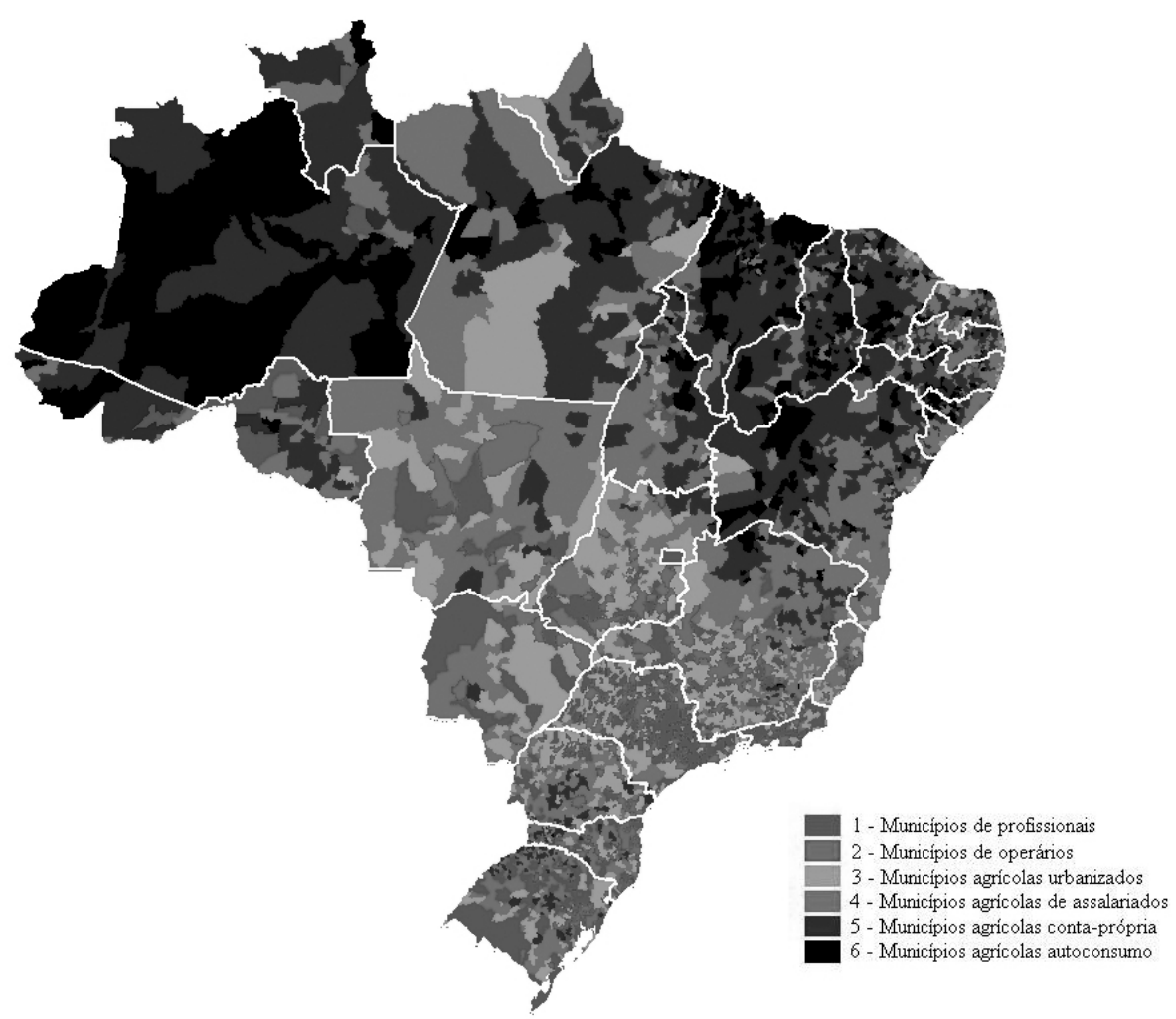

Fonte: Censo Demográfico 2000, microdados, IBGE. Elaboração dos autores. 
Na Região Norte, sobretudo no estado do Amazonas, está a segunda maior concentração de municípios agrícolas autoconsumo do País. São comunidades ribeirinhas com precárias condições de desenvolvimento socioconômico, onde o extrativismo ainda se mantém como a principal fonte de subsistência. Os poucos municípios de profissionais da região são, além das capitais estaduais, municípios dos estados de Rondônia e Tocantins que recentemente se beneficiaram com o avanço do agronegócio no cerrado e na borda sul da floresta amazônica.

No Nordeste, as três zonas climáticas bem definidas (Zona da Mata, Agreste e Sertão) exercem um papel muito claro na constituição da estrutura social dos municípios. De maneira geral, constata-se que, enquanto os municípios não-agrícolas e agrícolas mais desenvolvidos (grupos 3 e 4) concentram-se na Zona da Mata e no Agreste nordestino, no Sertão prevalecem os municípios agrícolas conta própria e autoconsumo. A Zona da Mata, que se estende pela faixa litorânea atlântica nordestina, concentra as forças produtivas mais desenvolvidas da região - herança da base econômica formada na produção de açúcar e algodão para o mercado externo - e os setores associados à exploração do potencial turístico de seu exuberante litoral. Na área de transição entre a Zona da Mata e o Sertão semi-árido está o Agreste, formado historicamente como uma espécie apêndice econômico da Zona da Mata, produzindo alimentos para essa área mais desenvolvida da região. Já a extensa área do Sertão nordestino é a mais isolada geográfica, econômica, e culturalmente. As irregulares ocorrências de chuva nessa região provocam secas cíclicas ou periódicas, castigando a população que sobrevive da pecuária extensiva, da agricultura de subsistência e de baixa produtividade. Aos condicionantes climáticos aliam-se problemas de origem estrutural, como a concentração de terras nas mãos dos coronéis latifundiários, o isolamento geográfico e o atraso social de sua população.

A Região Centro-Oeste, sustentada pela riqueza proporcionada pelo agronegócio, já começa a alavancar uma segunda onda de expansão da economia, baseada na industrialização, na inovação tecnológica e na prestação de serviços, o que acaba refletindo nos padrões sociais de sua população. A região apresenta uma composição relativamente diversificada, com pouquíssimos municípios agrícolas menos desenvolvidos (conta própria e autoconsumo), $23 \%$ de municípios não-agrícolas e $34 \%$ de agrícolas urbanizados.

A Região Sul, colonizada, sobretudo na base da pequena e média propriedade agrícola, apresentava, em 2000, uma configuração espacial relativamente equilibrada, com uma pequena participação de municípios agrícolas autoconsumo e poucas diferenças entre as participações dos demais perfis sociais. Na parte centro-oeste, próxima à tríplice fronteira com a Argentina 
e o Paraguai, concentram-se os municípios menos desenvolvidos da região, dos perfis agrícolas 4 e 5. É historicamente uma região com grau de urbanização relativamente baixo, onde predomina a pequena propriedade rural baseada na agroindústria e na agropecuária familiar 6 . Já a classificação dos municípios de profissionais no extremo sul do Rio Grande do Sul (Mesorregião Metade Sul) pode parecer um contraste em uma região historicamente caracterizada por extensas áreas de pecuária e produção de arroz, além de baixo desenvolvimento social (KAGEYAMA, 2005), mas se justifica pela estrutura social de sua população. Tal fenômeno sugere que, embora as atividades agrícolas possam prevalecer na área da região, não prevalecem no estilo de vida da população, o que pode ser devido ao pequeno emprego de mão-de-obra nas atividades agropecuárias ${ }^{7}$.

Para finalizar, o Sudeste apresenta a estrutura social mais desenvolvida entre as grandes regiões. Os estados de São Paulo e Rio de Janeiro apresentam a maior participação de municípios com as estruturas mais desenvolvidas, com taxas equivalentes a $60 \%$ e $79 \%$ de seus municípios nos perfis 1 e 2 , respectivamente. Mesmo com as ações tomadas nas últimas décadas para redução da concentração regional - como a migração da agroindústria ao Centro-Oeste e Norte do País, bem como o deslocamento de parte da indústria de transformação para as Regiões Sul e Nordeste - o Sudeste, em particular o estado de São Paulo, ainda se mantém na liderança da geração de riqueza. Mais da metade da riqueza do País continua sendo produzida na região, sendo que só o estado de São Paulo responde por $32 \%$ de todo o PIB nacional ${ }^{8}$. Espacialmente, se observa um eixo integrado de desenvolvimento em direção ao noroeste do estado, cujas raízes podem ser encontradas em uma série de políticas de incentivos do governo estadual e federal, determinantes do que CANO (1998) chama de processo de desconcentração industrial Grande São Paulo-Interior. No outro extremo, o norte de Minas Gerais apresenta padrões espaciais muito semelhantes aos estados vizinhos da região Nordeste, com prevalência de municípios dos três últimos estágios de desenvolvimento da estrutura social.

\footnotetext{
${ }^{6}$ A economia é baseada na agroindústria e na agropecuária, com a produção de grãos, suínos, aves, gado de corte e leite, frutas, erva-mate e fumo (Fonte: Portal da Mesorregião Grande Fronteira Mercosul, disponível em <http://www.mesorregiao-gfm.org.br/ caracterizacao.html>. Acessado em: jan. 2006)

${ }^{7}$ Fenômeno semelhante se observa na região centro-oeste, na qual, embora a atividade agropecuária ocupe áreas significativas do território, ocupa pouca mão-de-obra e não prevalece na estrutura social.

${ }^{8}$ O PIB da Região Sudeste corresponde a 56\% do PIB nacional (Fonte: PIB Municipal 2003, disponível em <http: \www.ibge.gov.br>. Acessado em: jan. 2006).
} 


\section{Desigualdades territoriais}

Para avaliar a composição e poder discriminatório dos perfis sociais em relação às características sociais, econômicas e demográficas, analisou-se sua composição segundo sexo, cor, idade, escolaridade, infra-estrutura domiciliar, além da distribuição de renda e população. O poder discriminatório dos perfis sociais em relação a cada característica baseou-se no coeficiente de determinação da Análise de Variância (FISHER, 1946).

Seja $\bar{X}$ a média da característica de interesse e $\bar{X}_{i}$ a média para o $i$-ésimo grupo municipal $(i=1 . . g)$, o qual contém $n_{i}$ municípios. A razão entre a variabilidade devida às diferenças entre os perfis e a variabilidade total permite avaliar o grau de determinação da relação. Em outras palavras, o coeficiente de determinação $R^{2}$ para a relação será dado por:

$$
R^{2}=\frac{\sum_{i=1}^{g} n_{i}\left(\bar{X}_{i}-\bar{X}\right)^{2}}{\sum_{i=1}^{g} \sum_{j=1}^{n_{i}}\left(X_{i j}-\bar{X}\right)^{2}}
$$

A análise dos resultados sugere que os perfis municipais cumprem um importante papel na diferenciação dos padrões sociais, econômicos e demográficos dos municípios. O menor poder discriminatório $\left(R^{2}\right.$ de $\left.10 \%\right)$ foi observado na relação com o sexo das pessoas, na qual há ainda uma tênue maior participação das mulheres nos municípios mais desenvolvidos (Tabela 2). Estas estão mais associadas às classes de domésticos e profissionais, que prevalecem justamente nos centros urbanos mais desenvolvidos.

Já em relação à participação dos negros, taxas mais elevadas são observadas nos municípios menos desenvolvidos, alcançando $70 \%$ nos municípios rurais autoconsumo. A percentagem de menores de 10 anos também é inversamente proporcional ao estágio de desenvolvido do município e se deve, sobretudo, à maior taxa de natalidade, menor expectativa de vida e maior êxodo de jovens e adultos dessas localidades menos desenvolvidas aos grandes centros urbanos. Enquanto as crianças menores de 10 anos de idade representam mais de 26\% da população nos municípios agrícolas autoconsumo, são menos de $18 \%$ da população nos municípios urbanos profissionais. Para ambas as características, cor ou raça e crianças menores de 10 anos, o poder discriminatório dos perfis sociais é superior a $30 \%$.

Os indicadores para grau de escolaridade chamam atenção para o baixo nível educacional do brasileiro e também mostram uma clara relação de dependência 
com o estágio de desenvolvimento sociocupacional dos municípios. A percentagem da população adulta ( 20 anos ou mais de idade) com $2^{\circ}$ ou $3^{\circ}$ grau de escolaridade (completo ou incompleto) é pouco superior a 31\% no Brasil e está concentrada nos municípios mais urbanizados. Para se ter uma idéia, $82 \%$ dos adultos com $3^{\circ}$ grau de escolaridade estão nos municípios de profissionais, no qual estes representam apenas 15\% de sua população. Nos municípios agrícolas, a percentagem média de adultos com no máximo $1^{\circ}$ grau de escolaridade é igual ou superior a $78 \%$ e chega a $91 \%$ nos municípios agrícolas autoconsumo. Os perfis sociais mostram ainda um relevante poder discriminatório em relação ao nível de escolaridade, chegando a $62 \%$ no caso da participação de adultos com $3^{\circ}$ grau de escolaridade.

Tabela 2. Características sociais dos municípios segundo perfil social - Brasil 2000

\begin{tabular}{|c|c|c|c|c|c|c|c|}
\hline \multirow{2}{*}{$\begin{array}{l}\text { Perfil } \\
\text { Social }\end{array}$} & \multirow{2}{*}{$\begin{array}{c}\% \\
\text { Mulheres }\end{array}$} & \multirow{2}{*}{$\begin{array}{c}\% \\
\text { Negros }\end{array}$} & \multirow{2}{*}{$\begin{array}{c}\% \\
<10 \text { anos }\end{array}$} & \multicolumn{4}{|c|}{ Pessoas com 20 anos ou mais } \\
\hline & & & & $\begin{array}{l}\text { \% Sem } \\
\text { Estudo }\end{array}$ & $\begin{array}{c}\% \\
\text { 10 Grau }\end{array}$ & $\begin{array}{c}\% \\
\text { 2o Grau }\end{array}$ & $\begin{array}{c}\% \\
\text { 3o Grau }\end{array}$ \\
\hline 1 & 51,8 & 37,0 & 17,4 & 7,2 & 51,2 & 26,4 & 15,2 \\
\hline 2 & 50,3 & 36,3 & 19,2 & 9,6 & 63,6 & 20,8 & 6,0 \\
\hline 3 & 49,7 & 47,3 & 20,2 & 17,5 & 60,5 & 17,7 & 4,4 \\
\hline 4 & 49,8 & 58,6 & 21,4 & 27,9 & 54,5 & 14,5 & 3,1 \\
\hline 5 & 49,3 & 66,8 & 24,0 & 37,6 & 50,3 & 10,5 & 1,6 \\
\hline 6 & 48,9 & 70,1 & 26,7 & 44,1 & 47,3 & 7,8 & 0,8 \\
\hline Total & 50,8 & 45,0 & 19,4 & 14,7 & 54,0 & 21,5 & 9,8 \\
\hline $\mathrm{R}^{2}$ & 0,099 & 0,310 & 0,366 & 0,551 & 0,220 & 0,470 & 0,616 \\
\hline
\end{tabular}

Fonte: Censo Demográfico 2000, microdados, IBGE; Divisão Territorial Brasileira de 2001 (IBGE) disponível no Atlas Brasil (INPE). Elaboração dos autores.

A hierarquia de tamanho e densidade populacional definida pelo estágio de desenvolvimento da estrutura social (Tabela 3) também sugere uma relativa convergência a um dos pontos consensuais na inesgotável discussão da literatura sobre a definição de espaços rurais e urbanos (KAGEYAMA, 2004). Com uma população de aproximadamente 85 milhões de habitantes, os municípios de profissionais apresentariam o estágio mais avançado de urbanização e, no extremo oposto, os municípios agrícolas, o menor estágio. Os municípios profissionais concentravam metade da população brasileira no ano de 2000 em uma área correspondente a apenas 10\% do território nacional. Apresentavam a maior renda média (430 reais per capita), eram os mais populosos (média de quase $150 \mathrm{mil}$ habitantes por município) e os mais densamente povoados (média de $117 \mathrm{hab} / \mathrm{km}^{2}$ ). 
Logo após, aparecem os municípios de operários, com uma população média de 38 mil habitantes por município e densidade média de 62 habitantes $/ \mathrm{km}^{2}$. Já os 4 perfis restantes de municípios agrícolas apresentam baixas densidades populacionais e baixas rendas per capita. São municípios pequenos e pobres, no qual o tamanho médio não ultrapassa 15 mil habitantes, a densidade média é inferior a 13 habitantes $/ \mathrm{km}^{2}$ e a renda per capita não chega a 193 reais mensais.

Os municípios agrícolas de assalariados predominam no Brasil e representam $31 \%$ do total de municípios. Chama também atenção o extenso espaço ocupado pelos 345 municípios do grupo mais precário $(6 \%$ dos municípios ocupando $17 \%$ da área total brasileira), em que prevalecem as atividades de autoconsumo em áreas semidesérticas com densidade pouco superior a 3 habitantes por $\mathrm{km}^{2}$ e renda per capita não superior a 60 reais mensais.

Tabela 3. Características demográficas e econômicas dos municípios segundo perfil social - Brasil 2000

\begin{tabular}{ccccccccc}
\hline \multirow{2}{*}{$\begin{array}{c}\text { Perfil } \\
\text { Social }\end{array}$} & \multicolumn{2}{c}{ Municípios } & \multicolumn{2}{c}{ População } & População & $\begin{array}{c}\text { \% Área } \\
\text { Total }\end{array}$ & $\begin{array}{c}\text { Densidade } \\
\left(\mathbf{h a b} / \mathbf{k m}^{2}\right)\end{array}$ & $\begin{array}{c}\text { Rnd P } \\
\text { Cap }\end{array}$ \\
\hline 1 & 577 & 10,5 & 84.769 .550 & 49,9 & 146.914 & 8,6 & 116,7 & 430,0 \\
2 & 609 & 11,1 & 23.067 .609 & 13,6 & 37.878 & 4,4 & 62,2 & 258,3 \\
3 & 1.016 & 18,4 & 14.247 .780 & 8,4 & 14.023 & 13,9 & 12,2 & 192,7 \\
4 & 1.732 & 31,5 & 25.978 .254 & 15,3 & 14.999 & 26,2 & 11,8 & 136,8 \\
5 & 1.228 & 22,3 & 17.351 .053 & 10,2 & 14.130 & 30,2 & 6,8 & 88,5 \\
6 & 345 & 6,3 & 4.458 .611 & 2,6 & 12.924 & 16,7 & 3,2 & 58,5 \\
Total & 5.507 & 100,0 & 169.872 .856 & 100,0 & 30.847 & 100,0 & 20,2 & 297,3 \\
\hline
\end{tabular}

${ }^{1}$ Valores em Janeiro de 2005 (INPC corrigido para o Censo Demográfico - IPEA)

Fonte: Censo Demográfico 2000, microdados, IBGE; Divisão Territorial Brasileira de 2001 (IBGE) disponível no Atlas Brasil (INPE). Elaboração dos autores.

Embora haja uma direta relação entre os rendimentos médios per capita e o estágio de desenvolvimento da estrutura social, não seria adequado analisá-la sem o conhecimento do grau de desigualdade intra e intermunicipal, já que os rendimentos médios tendem a ser fortemente influenciados por valores extremos da distribuição. Para cumprir tal objetivo, a Tabela 4 apresenta os valores de alguns dos principais indicadores de concentração de renda da literatura (HOFFMANN, 1998), estimados sobre os rendimentos per capita dos integrantes familiares: percentagem de renda apropriada pelos $40 \%$ mais pobres e 10\% mais ricos, índice de concentração (razão entre a renda apropriada pelos $10 \%$ mais ricos e $40 \%$ mais pobres), índice de Gini e T de Theil.

Mesmo com significativas diferenças entre os perfis sociais, os elevados índices de concentração de renda observados em todos os grupos retratam a realidade brasileira de extrema desigualdade (BARROS et al.., 2000). Nos 
municípios de profissionais os 10\% mais ricos apropriam-se da maior parcela dos rendimentos totais (50\%). Entretanto, nos municípios com as estruturas sociais menos desenvolvidas, principalmente agrícolas conta própria e autoconsumo, a concentração de renda é maior e mais acentuada nos extremos da distribuição. Ou seja, evidencia-se nesses municípios uma maior diferença entre a massa de rendimentos apropriada pelos relativamente ricos e relativamente pobres.

Tabela 4. Indicadores de concentração de renda segundo perfil social - Brasil 2000

\begin{tabular}{ccccccc}
\hline & \multicolumn{2}{c}{ \% Rnd Apropriada } & & \multicolumn{2}{c}{ T Theil $^{1}$} \\
\cline { 2 - 3 } Perfil Social & $\begin{array}{c}\mathbf{4 0 \%} \text { mais } \\
\text { pobres (A) }\end{array}$ & $\begin{array}{c}\mathbf{1 0 \%} \text { mais } \\
\text { ricos (B) }\end{array}$ & IC (B/A) & Índice Gini & \% Dentro & \% Entre \\
\hline 1 & 7,5 & 49,6 & 6,6 & 0,622 & 93,3 & 6,7 \\
2 & 10,7 & 41,5 & 3,9 & 0,534 & 96,9 & 3,1 \\
3 & 9,1 & 47,6 & 5,3 & 0,585 & 96,0 & 4,0 \\
4 & 7,5 & 49,8 & 6,7 & 0,617 & 92,4 & 7,6 \\
5 & 6,3 & 48,6 & 7,7 & 0,626 & 94,4 & 5,6 \\
6 & 4,0 & 48,6 & 12,2 & 0,651 & 96,6 & 3,4 \\
Total & $\mathbf{6 , 2}$ & $\mathbf{5 2 , 6}$ & $\mathbf{8 , 5}$ & $\mathbf{0 , 6 5 2}$ & $\mathbf{8 1 , 2}$ & $\mathbf{1 8 , 8}$ \\
\hline
\end{tabular}

${ }^{1} \mathrm{~T}$ de Theil decomposto para estimar a desigualdade dentro dos municípios e entre os municípios.

Fonte: Censo Demográfico 2000, microdados, IBGE. Elaboração dos autores.

O índice $\mathrm{T}$ de Theil foi decomposto para captar as desigualdades dentro $(\%$ Dentro) e entre (\% Entre) os municípios de cada grupo. De maneira geral, constata-se que quase $4 / 5$ da desigualdade total é devida às diferenças intramunicipais. A segmentação dada pelos perfis sociais reduziu, entretanto, em mais de $50 \%$, ou 11 pontos percentuais, a desigualdade entre os municípios, ou seja, as diferenças entre os rendimentos apropriados pelos municípios de um mesmo perfil social são consideravelmente inferiores às do conjunto total de municípios. A desigualdade entre os municípios de operários e agrícolas autoconsumo é mínima, equivalente a apenas 3\% da desigualdade total, e é máxima entre os municípios agrícolas conta própria, equivalente a $8 \%$ da desigualdade total.

Outro tema de relevância na mensuração da qualidade de vida e no estudo das diferenças sociais é o acesso à infra-estrutura domiciliar. Segundo BELTRÃO \& SUGAHARA (2005), a infra-estrutura domiciliar é condição necessária, embora não suficiente, para o desenvolvimento econômico e social. Como sugerem os mesmos autores, a infra-estrutura básica é parte essencial da qualidade de vida dos cidadãos, devendo constar em qualquer agenda de discussão sobre metas sociais ao lado de temas como redução da pobreza, melhoria do padrão de vida, educação, saúde, entre outros. É também essencial para o desenvolvimento 
econômico, na medida em que dinamiza os hábitos de consumo e o aumento da renda da população. $\mathrm{O}$ acesso à energia elétrica, por exemplo, estimula o consumo de eletrodomésticos e é essencial para viabilizar a produção de pequenos empreendedores.

A discriminação dos municípios brasileiros segundo padrões de infra-estrutura domiciliar foi feita neste trabalho segundo onze indicadores: acesso da população à água canalizada (independente da proveniência), luz elétrica, esgotamento sanitário (rede coletora geral ou pluvial, fossa séptica ligada ou não à rede coletora de esgoto), coleta de lixo, pelo menos um sanitário de uso privativo do domicílio, telefone fixo, computador, geladeira, máquina de lavar, televisão em cores e automóvel. São todos indicadores dicotômicos, ou seja, assumem valor unitário quando o integrante familiar apresenta uma ou mais das características no domicílio em que mora e valor nulo caso contrário. Para viabilizar a comparação entre os perfis no que se refere ao conjunto das características de infra-estrutura domiciliar, criou-se ainda um indicador sintético de infra-estrutura domiciliar (ISIED) calculando uma média aritmética simples dos percentuais de acesso para cada característica. Assim, o ISIED irá oscilar entre o mínimo de 0 ( $0 \%$ de acesso a todas as características) ao máximo de 100 (100\% de acesso em todas as características). Nas análises, foram consideradas as famílias residentes em todos os tipos de domicílios: particulares permanentes; particulares improvisados e coletivos ${ }^{9}$. Integrantes de famílias independentes que compartilham o domicílio herdaram as mesmas características de infra-estrutura domiciliar.

Há diferenças significativas entre os perfis sociais municipais mesmo quando se tratam de serviços básicos essenciais para a qualidade de vida da população, como acesso à água canalizada e luz elétrica (Tabela 5). Nos municípios agrícolas autoconsumo, por exemplo, menos de $1 / 5$ da população tinha acesso à água canalizada e pouco mais de $3 / 5$ possuía luz elétrica no domicílio, contra taxas próximas a 100\% nos municípios de profissionais e operários.

\footnotetext{
${ }^{9}$ O IBGE classifica os domicílios em particulares permanentes, particulares improvisados e coletivos. Pelas definições do IBGE (1995), domicílio particular permanente é aquele localizado em unidade que se destina a servir de moradia (casa, apartamento ou cômodo). Domicílio particular improvisado é aquele localizado em dependência que não seja destinada exclusivamente à moradia (sala comercial, prédio em construção, embarcação, carroça, vagão, tenda, barraca, gruta, etc.). E os domicílios coletivos são aqueles destinados à habitação de pessoas em cujo relacionamento prevalecesse o cumprimento de normas administrativas (hotéis, pensões, presídios, cadeias, penitenciárias, quartéis, postos militares, asilos, orfanatos, conventos, hospitais e clínicas - com internação - motéis, camping, etc.). Os domicílios particulares permanentes são, entretanto, ampla maioria na população. Em 2004, foram amostrados 112.530 domicílios particulares permanentes $(99,8 \%)$, contra 118 domicílios particulares improvisados e 68 domicílios coletivos (Fonte: PNAD, microdados, IBGE).
} 
Tipologia municipal de classes sociocupacionais:

uma nova dimensão para análise das desigualdades territoriais no Brasil

Definiu-se, ainda, uma clara hierarquia entre os perfis sociais no que se refere às condições gerais de infra-estrutura domiciliar, o que sugere a consistência da tipologia de estratificação na identificação do grau de urbanidade/ruralidade dos municípios. O ISIED do perfil social 1, por exemplo, é 3,7 vezes superior ao do perfil 6 e apenas $8 \%$ superior ao do perfil 2 . Entre os perfis agrícolas as diferenças também são substanciais: o ISIED do perfil 3, por exemplo, é 30\% superior ao do perfil $4,93 \%$ ao do perfil 5 e $184 \%$ superior ao do perfil 6 .

De maneira geral, os perfis sociais apresentaram expressivos poderes discriminatórios para todas as características de infra-estrutura domiciliar, oscilando entre o mínimo de 30\% para esgotamento sanitário e o máximo de $68 \%$ para coleta de lixo, e alcançando $75 \%$ para o ISIED.

Tabela 5. Percentual da população com acesso à infra-estrutura domiciliar segundo perfil social - Brasil 2000

\begin{tabular}{|c|c|c|c|c|c|c|c|c|}
\hline \multirow{2}{*}{$\begin{array}{l}\text { Acesso à } \\
\text { Infra-Estrutura }\end{array}$} & \multicolumn{6}{|c|}{ Perfil Social Municipal } & \multirow{2}{*}{ Total } & \multirow{2}{*}{$\mathbf{R}^{2}$} \\
\hline & 1 & 2 & 3 & 4 & 5 & 6 & & \\
\hline Água canalizada & 93,2 & 93,5 & 82,0 & 59,9 & 35,5 & 19,4 & 79,4 & 0,634 \\
\hline Esgotamento sanitário & 80,8 & 73,2 & 47,0 & 35,1 & 23,7 & 15,1 & 65,5 & 0,303 \\
\hline Coleta de lixo & 93,9 & 89,1 & 71,9 & 51,9 & 29,3 & 15,2 & 76,4 & 0,677 \\
\hline Luz elétrica & 99,5 & 99,3 & 96,3 & 87,3 & 71,6 & 60,7 & 93,5 & 0,463 \\
\hline Telefone fixo & 56,4 & 34,7 & 21,8 & 13,0 & 6,3 & 3,6 & 37,4 & 0,611 \\
\hline Sanitário & 94,5 & 95,7 & 83,8 & 62,8 & 36,8 & 21,3 & 81,1 & 0,667 \\
\hline Televisão em cores & 95,7 & 94,1 & 87,8 & 76,5 & 59,8 & 45,2 & 86,9 & 0,573 \\
\hline Geladeira & 95,0 & 94,5 & 82,4 & 64,0 & 43,7 & 30,7 & 82,2 & 0,654 \\
\hline Computador & 17,0 & 7,6 & 3,7 & 2,1 & 0,9 & 0,6 & 10,3 & 0,633 \\
\hline Máquina de lavar & 47,1 & 37,1 & 17,0 & 9,1 & 3,9 & 1,9 & 31,8 & 0,546 \\
\hline Automóvel & 42,6 & 37,4 & 26,6 & 17,2 & 9,3 & 4,9 & 32,3 & 0,520 \\
\hline ISIED & 74,2 & 68,7 & 56,4 & 43,5 & 29,2 & 19,9 & 61,5 & 0,751 \\
\hline
\end{tabular}

Fonte: Censo Demográfico 2000, microdados, IBGE. Elaboração dos autores.

\section{Conclusões}

Este trabalho apresentou uma nova proposta de configuração do espaço territorial brasileiro baseada na composição das estruturas sociais municipais, uma proxy do estilo de vida e dos níveis de bem-estar de suas populações. A idéia central era que o estágio de desenvolvimento da estrutura social municipal traria importantes elementos para compreender o quadro de extremas desigualdades existentes no espaço nacional. 
Utilizando técnicas estatísticas de análise multivariada, foram identificados seis grupos municipais (perfis sociais) que definem padrões sociais associados aos estágios de desenvolvimento das classes agrícolas e não-agrícolas de uma sociedade. Os dois primeiros perfis sociais representam municípios com características tipicamente urbanas, mais populosos e densamente povoados, no qual predominam as classes dos empregadores, profissionais (ambos no grupo 1) e da massa trabalhadora não-agrícola (grupo 2). Os municípios tipicamente rurais, com baixa densidade populacional e prevalência das classes agrícolas, distinguem-se, sobretudo, pela maior participação da massa trabalhadora (grupos 3 e 4), pequenos proprietários conta própria (grupo 5) e não-remunerados (grupo 6). Do grupo 1 ao grupo 6, a tendência é o aumento da participação de pobres e miseráveis dos estratos inferior e ínfimo (subclassificados) em todas as classes ocupacionais.

O problema da escala geográfica exige, entretanto, alguns cuidados especiais e impõe importantes limitações e desafios à análise. Mesmo municípios com elevados padrões sociais podem apresentar significativos bolsões de miséria em sua área intra-urbana, sendo que a análise espacial apenas apresentará os valores médios da população. A identificação desses subespaços geográficos constitui recorrente dificuldade para o equacionamento dos problemas sociais, seja por não serem adequadamente alcançados pelas políticas universais, seja por apresentarem dinâmicas sociais próprias que dificultam o acesso de suas populações às políticas públicas (SEADE, 2003).

A redução da dimensionalidade das complexas diferenças municipais em alguns grupos sociais acaba, indubitavelmente, provocando uma importante perda de informação. Embora alguns municípios do extremo sul gaúcho e as duas principais metrópoles brasileiras, São Paulo e Rio de Janeiro, por exemplo, tenham em comum uma maior participação relativa das classes de profissionais e empregadores em suas estruturas sociais, há ainda que se considerar significativas diferenças socioeconômicas entre as populações dessas regiões.

O complexo universo das desigualdades territoriais brasileiras exige, portanto, estudos mais apurados sobre as diferenças entre os municípios. Para ajudar a compreender este quadro, foram analisadas algumas das principais medidas de concentração dos rendimentos per capita da população. De maneira geral, constatou-se que a maior parcela da desigualdade entre os rendimentos per capita dos integrantes familiares se deve às diferenças intramunicipais $(81 \%)$. Entretanto, a estratificação segundo perfis sociais cumpriu um importante papel ao reduzir significativamente as diferenças entre os municípios, chegando a apenas 3\% no caso dos municípios de operários e municípios agrícolas autoconsumo. Também se observou que os municípios com as estrutura mais desenvolvidas, sobretudo os municípios de operários, apresentaram os menores índices de concentração de renda entre seus habitantes. Os dados ainda sugerem que os municípios agrícolas menos desenvolvidos apresentam uma estrutura 
mais concentrada nos extremos da distribuição de rendimentos, no qual a diferença entre a massa de rendimentos apropriada pelos relativamente ricos e relativamente pobres é mais acentuada.

A evidente hierarquia observada nos indicadores dos perfis sociais em relação à infra-estrutura domiciliar sugere ainda que a tipologia de estratificação identificou com relativa consistência o grau de urbanidade/ruralidade dos municípios brasileiros. Diferenças significativas foram observadas entre os perfis sociais municipais mesmo no que se refere a serviços básicos essenciais para a qualidade de vida da população, como acesso à água canalizada e luz elétrica. Observou-se também uma tênue maior participação feminina nos municípios mais desenvolvidos, associada, provavelmente, à maior prevalência nas classes de profissionais e domésticos, grupos característicos dos centros urbanos mais desenvolvidos. Os negros, por sua vez, estão nas ocupações da base da pirâmide social e predominam nos municípios rurais menos desenvolvidos, onde também prevalecem baixos índices de escolaridade e crianças menores de 10 anos de idade.

De maneira geral, a consistência dos relacionamentos dos perfis sociais com as características socioeconômicas de suas populações, assim como a convergência entre a espacialização obtida neste trabalho e os resultados da literatura baseados em uma diversidade de indicadores socioeconômicos (IBGE, 2008; THERY \& MELLO, 2004), destacam a importância da estrutura social, baseada na divisão social do trabalho, na formação da estrutura das sociedades capitalistas modernas e na configuração do território. Além de determinar, em grande medida, a probabilidade de geração de renda presente e futura das localidades, a estrutura social mostrou-se ainda capaz de discriminar diferentes padrões socioeconômicos brasileiros. Embora a distribuição espacial das classes ocupacionais e estratos sociais não pressuponha obrigatoriamente o reconhecimento da primazia da estrutura social como um princípio explicativo generalizado das diferenças territoriais, reafirma a idéia de que esta persiste como um determinante significativo e poderoso do grau de desenvolvimento socioeconômico do território.

Além de contribuir com uma nova dimensão para a análise da estrutura social brasileira, a configuração espacial obtida nesse trabalho é mais um importante instrumento para analisar as extremas diferenças territoriais brasileiras. Estudos mais apurados ainda poderão ser obtidos com outras dimensões de análises, além dos rendimentos per capita e acesso à infra-estrutura domiciliar, bem como análises focalizadas para regióes, estados ou mesmo municípios, utilizando, quando possível, áreas espaciais mais desagregadas, como os setores censitários disponibilizados pelo IBGE. 


\section{Referências Bibliográficas}

BARROS, R. P.; HENRIQUE, R., MENDONÇA, R. A estabilidade inaceitável: desigualdade e pobreza no Brasil. In: HENRIQUE, R. (Org.). Desigualdade e pobreza no Brasil. Rio de Janeiro: IPEA, p. 21-47, 2000.

BELTRÃO, K. I.; SUGAHARA, S. Infra-estrutura dos domicílios brasileiros: uma análise para o período 1981-2002. Rio de Janeiro: IPEA, Texto para discussão, n. 1077, 2005.

CÂMARA, G; MONTEIRO, A. M.; MEDEIROS, J. M.. Introdução à ciência da geoinformação. São José dos Campos: INPE, 2004.

CANO, W. Raízes da concentração industrial em São Paulo. Campinas: Instituto de Economia da UNICAMP, 1998.

CRIVISQUI, E. Presentación de los métodos de clasificación. Programa Presta, ULB, 1999.

CUADRAS, C. M. Métodos de análisis multivariante. Barcelona: EUNIBAR Editorial Universitária de Barcelona S. A., 1981.

FISHER, R. Statistical methods for research works. Edinburgh: Oliver \& Boyd, 1946.

HOFFMANN, R. Distribuição de renda: medidas de desigualdade e pobreza. São Paulo: Editora da USP, 1998.

INSTITUTO BRASILEIRO DE GEOGRAFIA E ESTATÍSTICA. Mapa da pobreza e desigualdade dos municípios brasileiros 2003. Rio de Janeiro: IBGE, 2008. DVD.

INSTITUTO DE PESQUISA ECONÔMICA APLICADA. Pobreza e mudança social volume 1. Comunicado da Presidência, n. 9, Brasília, 2008. Disponível em: < http://www.ipea.gov.br/sites/000/2/pdf/Pnad_2007_AnalisesPobreza.pdf > . Acesso em: janeiro de 2008.

KAGEYAMA, A. Desenvolvimento rural no Rio Grande do Sul. In: Colóquio de Agricultura Familiar e Desenvolvimento Rural do GEPAD, Porto Alegre. 2005. No prelo.

Desenvolvimento rural: conceito e medida. Cadernos de Ciência \& Tecnologia, Brasília, v. 21, n. 3, p. 379-408, 2004.

KAGEYAMA, A.; LEONE, E. T. Uma tipologia dos municípios paulistas com base em indicadores sociodemográficos. Campinas: IE/UNICAMP, Texto para discussão, n. 66, 1999. 
416 - Tipologia municipal de classes sociocupacionais:

uma nova dimensão para análise das desigualdades territoriais no Brasil

MILLS, W. A nova classe média. Tradução de Vera Borda. 3. ed. Rio de Janeiro: Zahar Editores, 1979.

NERI, M.; CARAVALHAES, L. (Coord) Miséria e a nova classe média na década da igualdade. Rio de Janeiro: FGV/IBRE, CPS, 2008.

QUADROS, W. J. A evolução da estrutura social brasileira: notas metodológicas. Texto para Discussão. Campinas: IE/UNICAMP, n.147, 2008.

ROCHA, S. A investigação do rendimento na PNAD - comentários e sugestões à pesquisa nos anos 2000. Rio de Janeiro: IPEA, Texto para Discussão, n. 899, 2002.

ROSE, D.; PEVALIN, D. J. The national statistics socio-economic classification: unifying official and sociological approaches to the conceptualization and measurement of social class. Colchester: University of Essex, ISER Working Papers. n. 4, 2001.

SEADE. Índice Paulista de Responsabilidade Social - continuidade e desdobramentos. São Paulo, 2003.

THERY, H.; MELLO, N. A. Atlas do Brasil: Disparidades e Dinâmicas do Território. EDUSP, 2003.

VALLE SILVA, N. Atualização da escala socio-econômica de ocupações para 1980.Rio de Janeiro: LNCC, 1985.

VEIGA, J. E.; FAVARETO, A.; AZEVEDO, C. M. A.; BITTENCOURT, G.; VECCHIATTI, K.; MAGALHÃES, R.; JORGE, R. O Brasil rural precisa de uma estratégia de desenvolvimento. Brasília: MDA/CNDRS/NEAD, Texto para Discussão, n. 1, 2001.

WRIGHT, E. O. Classes. Nova Iorque: Editora Verso. 344 p., 1985. 


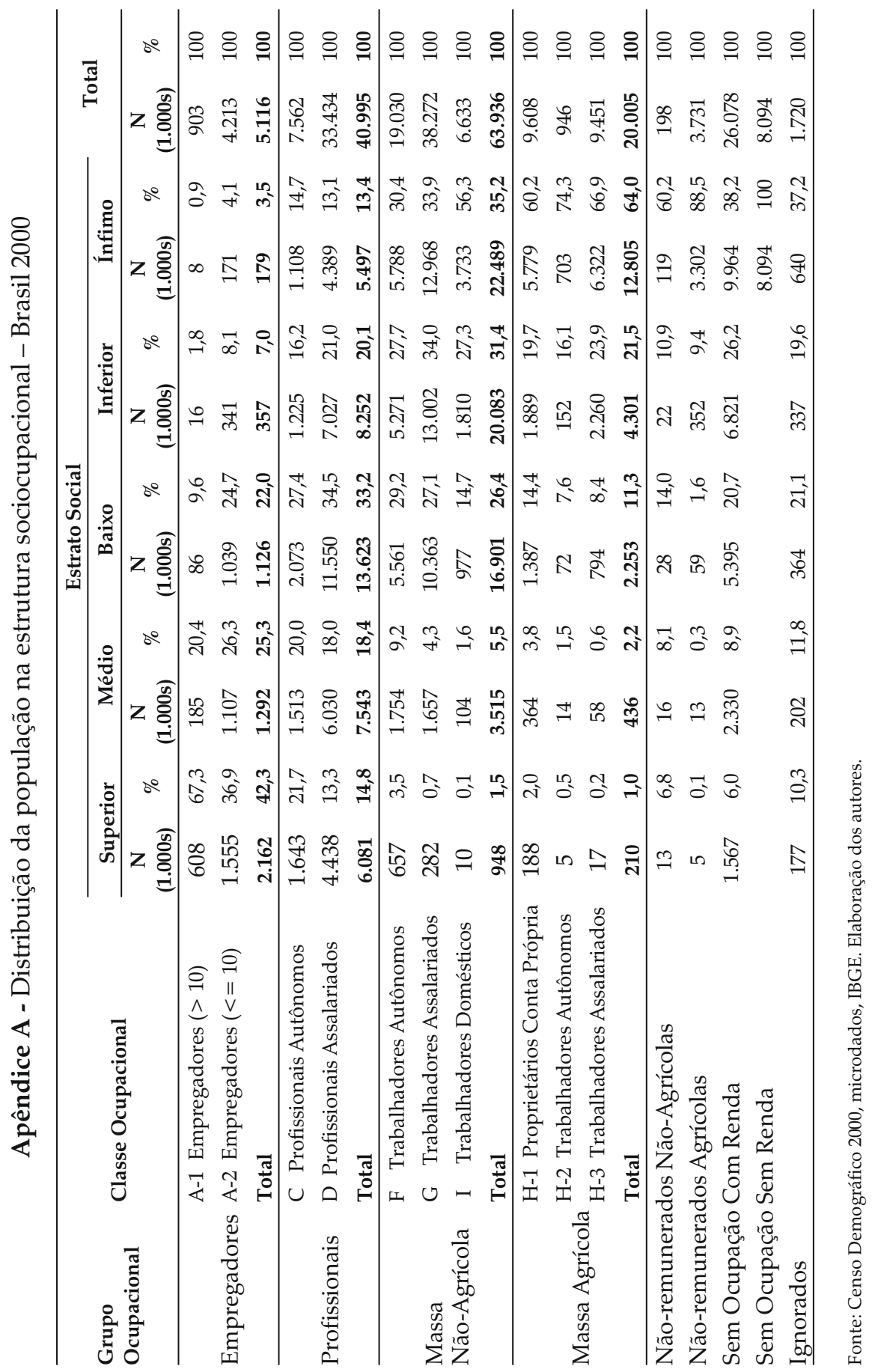

RESR, Piracicaba, SP, vol. 47, no 02, p. 389-418, abr/jun 2009 - Impressa em julho 2009 
418 - Tipologia municipal de classes sociocupacionais:

uma nova dimensão para análise das desigualdades territoriais no Brasil

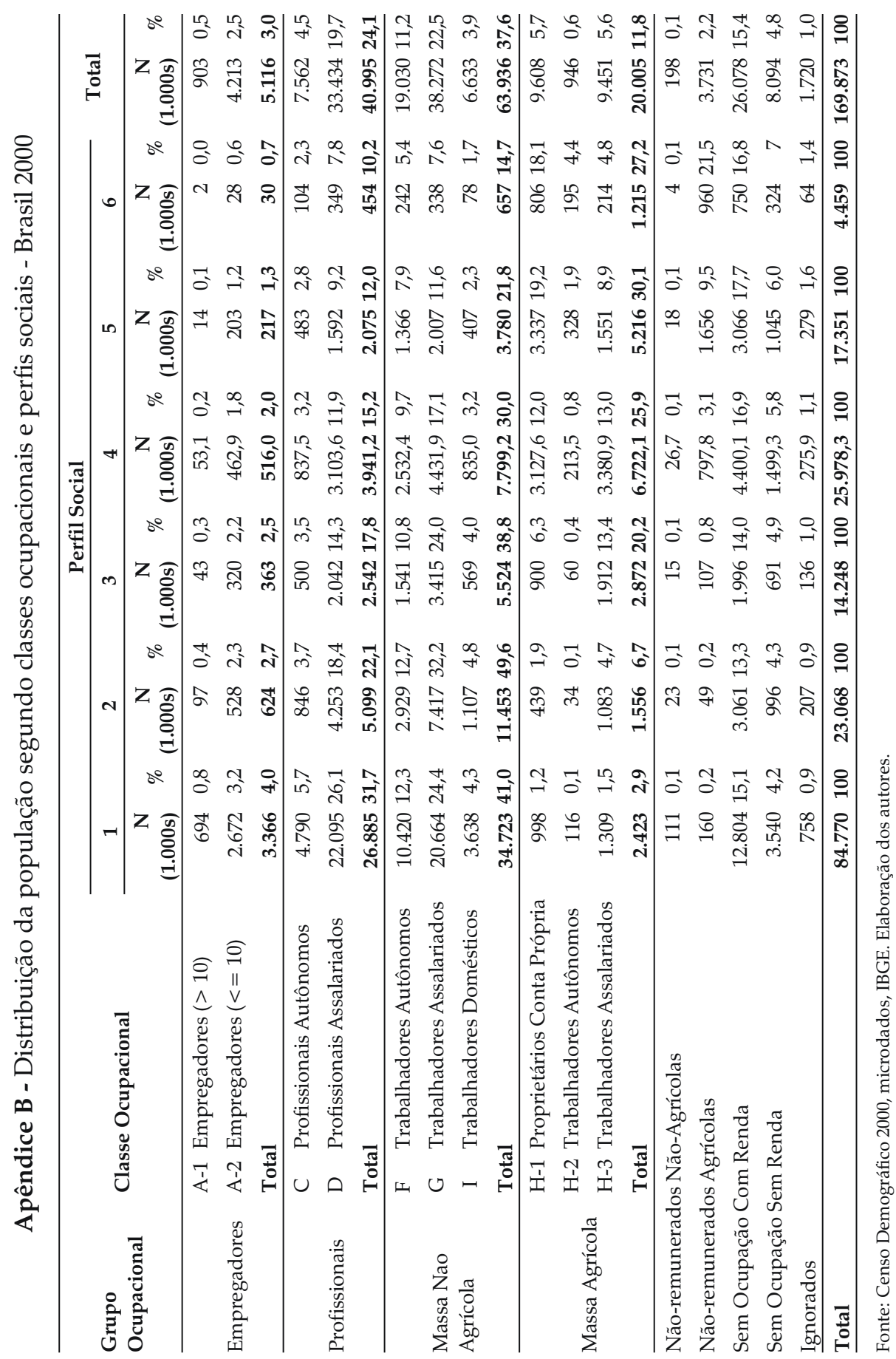

RESR, Piracicaba, SP, vol. 47, no 02, p. 389-418, abr/jun 2009 - Impressa em julho 2009 